\title{
Erratum to: Modeling and Analysis of Process Parameters for Evaluating Shrinkage Problems During Plastic Injection Molding of a DVD-ROM cover \\ H. Öktem
}

\section{Erratum to: J. of Materi Eng and Perform}

DOI 10.1007/s11665-011-9895-2

There are errors present in the values in the lower portion of Table 7.

These values should be corrected as follows:

$S=0.1035$

$R-\mathrm{Sq}=95.8 \%$

$R$-Sq(adj) $=95.0 \%$

PRESS $=0.351333$

$R-\mathrm{Sq}($ pred $)=93.68 \%$

The online version of the original article can be found under doi: 10.1007/s11665-011-9895-2.

H. Öktem, Gebze Vocational School, Department of Industrial Molding, University of Kocaeli, 41410 Çayırova, Kocaeli, Turkey. Contact e-mail: hoktem@kocaeli.edu.tr. 